\title{
Gamma knife radiosurgery for the treatment of uveal melanoma and uveal metastases
}

\author{
Margaret M. Reynolds ${ }^{1}$, Andrea L. Arnett ${ }^{2}$, lan F. Parney ${ }^{3}$, Ravi Kumar ${ }^{3}$, Nadia N. Laack ${ }^{2}$, Patrick R. Maloney ${ }^{3}$,
} Timothy F. Kozelsky ${ }^{2}$, Yolanda I. Garces ${ }^{2}$, Robert L. Foote ${ }^{2}$ and Jose S. Pulido ${ }^{1,4^{*}}$

\begin{abstract}
Background: This study retrospectively analyzed outcomes for patients undergoing gamma knife radiosurgery (GKR) for uveal melanoma (UM) and intraocular metastases.

Methods: Patients who underwent GKR for UM or intraocular metastases between 1/1/1990 and 6/1/2015 at Mayo Clinic, Rochester, MN, USA, were retrospectively analyzed.

Results: Eleven patients ( 11 eyes) had UM while seven patients (7 eyes) had intraocular metastases. Patients with UM were followed for a median of $19.74 \pm 10.4$ months. Visual acuity (VA) logMAR $0.30 \pm 0.53$ (Snellen 20/40) versus $0.40 \pm 0.97$ (Snellen 20/50), tumor thickness ( $5.30 \pm 2.17$ vs. $3.60 \pm 2.32 \mathrm{~mm}$ ), were not significantly different between preoperative and postoperative measurements, respectively. Nine percent (1/11) patients required enucleation. Subsequently, no patients experienced metastases. Patients with intraocular metastases were followed for a median of $6.03 \pm 6.32$ months. They did not have significant changes in VA (logMAR $0.30 \pm 0.59$ vs. $0.30 \pm 1.57$; Snellen 20/40 vs. 20/40) or tumor thickness ( $3.50 \pm 1.36$ vs. $1.30 \pm 0.76 \mathrm{~mm}$ ) postoperatively. Fourteen percent (1/7 patients) required enucleation. Complications experienced by patients with UM include radiation retinopathy (2/11), papillopathy (1/11), cystoid macular edema (1/11), vitreomacular traction (1/11), exudative retinal detachment (1/11). Patients with metastases had treatment complicated by recurrence (2/7). Dose to the margin, maximum dose of radiation, and clinical target volume did not correlate with post-procedural VA, risk of enucleation, or death in patients with either UM or patients with intraocular metastases.
\end{abstract}

Conclusions: Visual outcomes were satisfactory for patients undergoing GKR without significant morbidity and without significant risk of enucleation or metastases.

Keywords: Gamma knife, Intraocular metastasis, Stereotactic radiosurgery, Uveal melanoma, Uveal metastases

\section{Background}

Ocular metastases are the most common intraocular malignancy, while uveal melanoma (UM) is the most common primary intraocular malignancy. Cancer treatments have evolved to prioritize the most effective minimally invasive treatments with the fewest side effects. For these reasons, proton beam therapy, plaque

\footnotetext{
${ }^{*}$ Correspondence: pulido.jose@mayo.edu

${ }^{1}$ Department of Ophthalmology, Mayo Clinic, 200 First Street, SW, Rochester, MN 55905, USA

Full list of author information is available at the end of the article
}

brachytherapy, and gamma knife radiosurgery (GKR) have become more common. Recent studies have demonstrated that GKR has a similar efficacy to proton beam therapy and plaque brachytherapy [1-19].

Patients with cancer are living longer, resulting in higher rates of ocular metastases [20]. Patients with known malignancy have an estimated incidence of ocular involvement at $4-12 \%$ in post-mortem studies [18, 21-23] and clinical apparent malignancies in $2.3-5 \%$ of patients $[18,21,24]$. The most prevalent metastases have been reported to be breast carcinoma and lung carcinoma, which make up $80 \%$ of cases [25, 26]. Patients with 
uveal metastases have a relatively short life expectancy, with a mean survival of 7 months [18]. Still, without treatment, the metastatic disease is typically progressive with a poor visual prognosis and high ocular morbidity [18]. The goal of treatment for patients with ocular metastases is to decrease the tumor burden and ocular morbidity. Therefore, ocular treatments with the most efficacy, shortest duration of treatment, and fewest side effects are prioritized. For these reasons, proton beam therapy, plaque brachytherapy, and GKR have replaced external beam radiation, which requires weeks of treatment with more side effects.

Uveal melanoma is the most common primary intraocular malignancy in adults with an incidence of 5.1 per million people [27]. Since the Collaborative Ocular Melanoma Treatment Study (COMS) revealed that conservative treatments, such as brachytherapy, had the same survival outcome as surgical treatment, i.e. enucleation, physicians have prioritized more conservative treatment with the goal of preserving vision and eyes in patients with UM [28]. Both GKR and proton beam therapy have similar outcomes as enucleation and are, therefore, both utilized for treatment of large UMs [28, 29]. The goal of radiotherapy is to conserve the eye, destroy the tumor, and prevent local recurrence.

With similar efficacy to proton beam therapy and plaque brachytherapy, GKR also has some advantages. Unlike plaque brachytherapy, which requires two procedures on separate dates-placing and removing a plaque, GKR is a same-day procedure. Proton beam therapy facilities are resource intensive and not universally available.

Few reports have been published describing the use of GKR in eyes with UM and uveal metastases. We wish to report our results of patients that underwent GKR for $\mathrm{UM}$ and uveal metastases.

\section{Methods}

This study retrospectively analyzed patients with primary UM and uveal metastases who were treated with GKR at Mayo Clinic Rochester between 1/1/1990 and 6/1/2015. Approval was obtained from the Mayo Clinic Institutional Review Board.

Individuals considered for this study underwent GKR for choroidal metastases or primary UM. Patients were required to have at least one follow-up appointment. Data obtained from patient records included: date of birth, sex, oncologic diagnosis, preoperative and postoperative visual acuity (VA), tumor thickness, largest-base dimension (LBD), intraocular pressure (IOP), additional ophthalmic procedures such as enucleation, and postprocedural complications such as radiation retinopathy. Patients without follow-up and patients who underwent GKR for orbital rather than intraocular tumors were excluded. Patients were selected for GKR who were not candidates for plaque brachytherapy as they had melanomas, which were larger than the size of the largest plaque used for plaque brachytherapy $(24 \mathrm{~mm})$. GKR was chosen over enucleation after discussion with patients. During the period of this study, proton beam therapy was not yet available at Mayo Clinic, Rochester.

All included patients underwent GKR according to the following technique: retrobulbar block was performed. The Leksell stereotactic head frame was applied using local anesthetic and superficial fixation to the outer plate of the skull as described by Safaee et al. [30]. Patients underwent magnetic resonance imaging (MRI) with gadolinium contrast of the orbits and returned to the gamma knife center. Images were imported into the treatment planning system, Leksell GammaPlan, Elekta AB, Stockholm, Sweden. MRI and three-dimensional modeling was utilized to determine the tumor margins. A treatment plan was then developed in conjunction with a radiation oncologist, neurosurgeon, and ocular oncologist (Fig. 1). The clinical target volume (CTV) was determined to be the gross tumor volume (GTV) plus $2 \mathrm{~mm}$ on each side. The patient was transferred to the treatment unit, where the stereotactic GKR was performed. All patients were discharged the same day.

Categorical variables were compared between patients with uveal metastases and melanoma using the $\chi^{2}$ test, and two-sample $t$ tests were used to analyze continuous patient characteristics. Correlation tests were used to compare radiation doses and visual outcomes. Simple logistic models were constructed to determine variables associated with increased odds of enucleation and death. Statistical analyses were conducted using commercial software JMP (SAS Institute, Cary, NC, USA). All statistical tests were two-sided with a 0.05 level of significance.

\section{Results}

Eighteen patients met inclusion criteria; seven patients with uveal metastasis [lung adenocarcinoma $(\mathrm{n}=2)$, breast adenocarcinoma $(\mathrm{n}=1)$, renal cell carcinoma $(\mathrm{n}=1)$, cystic carcinoma $(\mathrm{n}=1)$, metastatic melanoma $(\mathrm{n}=1)$, esophageal carcinoma $(\mathrm{n}=1)]$ and 11 patients with primary UM.

Demographic characteristics are demonstrated in Table 1. Patients with UM were a median of $76.9 \pm 10.0$ years old. Patients had a median follow-up of $19.74 \pm 10.4$ (range 3.40-26.7) months. Of note, the three patients who succumbed to UM did so $<6$ months postoperatively. Patients who did not succumb to the illness were followed between 11.6 and 26.66 months (median: $22.1 \pm 7.47$ months). Patients with UM had tumors, which were a median of $5.30 \pm 2.17 \mathrm{~mm}$ thick by ultrasound with a preoperative LBD of $19.9 \pm 4.55 \mathrm{~mm}$. 

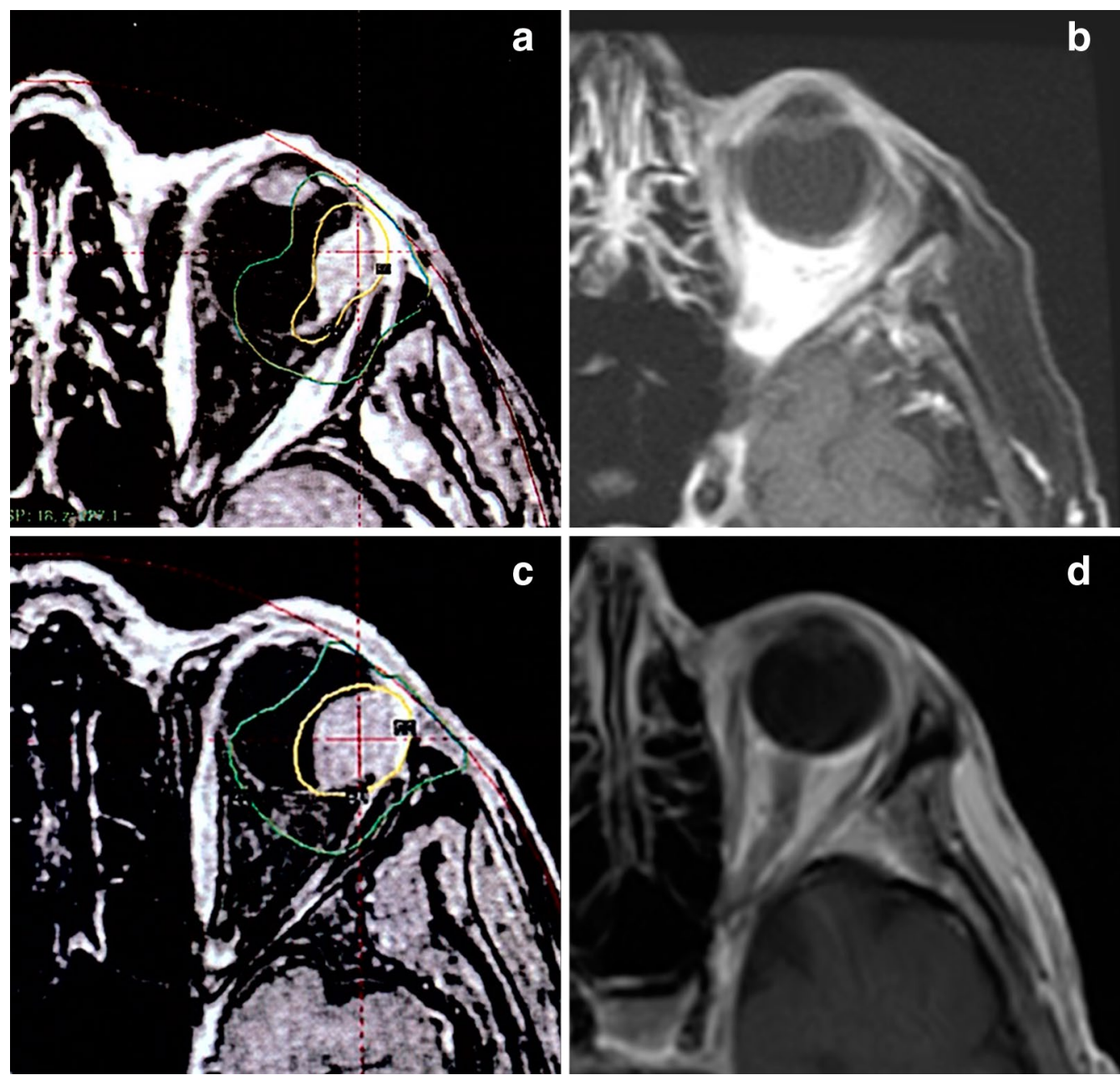

Fig. 1 a Representative gamma knife planning MRI of a patient with choroidal melanoma treated with 18 Gy at the $50 \%$ isodose line. b gadolinium-enhanced T2 MRI of the orbit of the same patient depicted in tile $\mathbf{a}$, after 7 months, shows interval decrease in size of choroidal mass. c Representative gamma knife planning MRI of a patient with choroidal melanoma treated with $27 \mathrm{~Gy}$ at the $50 \%$ isodose line. d Gadolinium-enhanced T2 fat saturation MRI of the orbit of the same patient depicted in tile $\mathbf{c}$, after 48 months, shows interval decrease in size of choroidal mass

Patients with UM were treated with a marginal dose of $25.0 \pm 3.36$ Gy at the $50 \%$ isodose line with a maximum median dose of $50.0 \pm 8.61$ Gy. The median CTV was $2250 \pm 747 \mathrm{~mm}^{3}$ (Table 2). Eight of eleven patients (72.7\%) were surviving at completion of the study. The final tumor thickness was $3.60 \pm 2.32 \mathrm{~mm}$, and postoperative LBD was $17.6 \pm 1.90 \mathrm{~mm}$ (Table 1 ).

Of the 10 patients with UM who did not undergo enucleation, VA increased by two or more lines in $0 \%(0 / 10)$, was stabilized in $70 \%$ (7/10 eyes), and decreased in $30 \%$ (3/10) due cystoid macular edema, radiation retinopathy, and exudative retinal detachment. In patients with UMs, VA, IOP, LBD, and tumor thickness were not significantly different postoperatively (Table 3 ). Notably, the tumor thickness was less postoperatively $5.30 \pm 2.17$ versus
$3.60 \pm 2.32 \mathrm{~mm}$, but this was not statistically significant $(\mathrm{p}=0.07)$, perhaps due to small study size. Dose to the margin, maximum dose of radiation, and CTV did not correlate with post-procedural VA, IOP, risk of enucleation, or death in patients with UM.

Of the included patients with UM, 18\% (2/11) experienced radiation retinopathy, $9 \%(1 / 11)$ underwent enucleation, 27\% (3/11) had papillopathy, 9\% (1/11) had cystoid macular edema, 9\% (1/11) had vitreomacular traction, and $9 \%(1 / 11)$ had exudative retinal detachment (Table 4). Finally, one patient with UM underwent enucleation after the tumor did not respond and demonstrated growth post-procedurally.

Patients with metastases were a median of $59.0 \pm 12.8$ years. Patients had a median follow-up of 
Table 1 Demographic characteristics of patients undergoing gamma knife radiosurgery

\begin{tabular}{lll}
\hline & Melanoma & Metastases \\
\hline Age at gamma knife (years) & $76.9 \pm 10.0$ & $59.0 \pm 12.8$ \\
Female (\%) & 63.6 & 28.5 \\
Length of follow-up (months) & $19.74 \pm 10.4$ & $6.03 \pm 6.32$ \\
Survival (\%) & 72.7 & 14.3 \\
Tumor recurrence (\% recurrence) & 0 & 28.6 \\
$\begin{array}{l}\text { Pre-op tumor thickness } \\
\text { by ultrasound (mm) }\end{array}$ & $5.30 \pm 2.17$ & $3.50 \pm 1.36$ \\
Post-op tumor thickness by & $3.60 \pm 2.32$ & $1.30 \pm 0.76$ \\
$\quad$ ultrasound (mm) & & \\
Pre-op VA (logMAR/Snellen) & $0.30 \pm 0.53 / 20 / 40$ & $0.30 \pm 0.59 / 20 / 40$ \\
Pre-op IOP (mmHg) & $14.0 \pm 2.40$ & $14.0 \pm 7.31$ \\
VA at last follow-up (logMAR/ & $0.40 \pm 0.97 / 20 / 50$ & $0.30 \pm 1.57 / 20 / 40$ \\
$\quad$ Snellen) & & \\
IOP at last follow-up (mmHg) & $15.0 \pm 3.49$ & $17.0 \pm 3.39$ \\
Enucleation (\%) & 9.09 & 14.3 \\
Largest base dimension pre-op & $19.9 \pm 4.55$ & $14.0 \pm 5.55$ \\
$\quad$ (mm) & & \\
Largest base dimension post-op & $17.6 \pm 1.90$ & $13.50 \pm 9.62$ \\
\hline
\end{tabular}

Table 2 Gamma knife treatment parameters

\begin{tabular}{lcc}
\hline & Melanoma & Metastases \\
\hline Maximum dose of radiation (Gy) & $50.0 \pm 8.61$ & $44.0 \pm 5.52$ \\
$50 \%$ isodose (Gy) & $25.0 \pm 3.36$ & $20.0 \pm 2.34$ \\
Clinical target volume $\left(\mathrm{mm}^{3}\right)$ & $2250 \pm 747$ & $1770 \pm 2791$ \\
\hline
\end{tabular}

Table 3 Preoperative versus postoperative demographic characteristics for patients with uveal melanoma and metastases

\begin{tabular}{llll}
\hline & Pre-op & Post-op & p value \\
\hline $\begin{array}{l}\text { Melanoma } \\
\text { Visual acuity } \\
\quad \text { logMAR/Snellen }\end{array}$ & $0.30 \pm 0.53 / 20 / 40$ & $0.40 \pm 0.97 / 20 / 40$ & 0.27 \\
IOP & $14.0 \pm 2.40$ & $15.0 \pm 3.49$ & 0.62 \\
$\begin{array}{l}\text { Tumor thickness } \\
\text { (mm) }\end{array}$ & $5.30 \pm 2.17$ & $3.60 \pm 2.32$ & 0.07 \\
$\begin{array}{l}\text { Largest base } \\
\text { dimension (mm) }\end{array}$ & $19.9 \pm 4.55$ & $17.6 \pm 1.90$ & 0.43 \\
$\begin{array}{l}\text { Uveal metastases } \\
\text { Visual acuity } \\
\quad \text { logMAR/Snellen }\end{array}$ & $0.30 \pm 0.59 / 20 / 40$ & $0.30 \pm 1.57 / 20 / 40$ & 0.76 \\
$\begin{array}{l}\text { IOP } \\
\text { Tumor thickness } \\
\text { (mm) }\end{array}$ & $14.0 \pm 7.31$ & $17.0 \pm 3.39$ & 0.92 \\
$\begin{array}{l}\text { Largest base } \\
\text { dimension (mm) }\end{array}$ & $14.0 \pm 5.55$ & $11.30 \pm 0.76$ & 0.01 \\
\hline
\end{tabular}

Table 4 Complications experienced by patients undergoing gamma knife radiosurgery

\begin{tabular}{lll}
\hline & Melanoma & Metastases \\
\hline Length of follow-up (months) & $19.74 \pm 10.4$ & $6.03 \pm 6.32$ \\
Radiation retinopathy & $2 / 11$ & $0 / 7$ \\
Vitreous hemorrhage & $0 / 11$ & $0 / 7$ \\
Neovascular glaucoma & $0 / 11$ & $0 / 7$ \\
Recurrence & $0 / 11$ & $2 / 7$ \\
Enucleation & $1 / 11$ & $1 / 7$ \\
Papillopathy & $1 / 11$ & $0 / 7$ \\
Cystoid macular edema & $1 / 11$ & $0 / 7$ \\
Vitreomacular traction & $1 / 11$ & $0 / 7$ \\
Exudative retinal detachment & $1 / 11$ & $0 / 7$ \\
\hline
\end{tabular}

$6.03 \pm 6.32$ (range 3.28-22.07) months. Tumor thickness was a median of $3.50 \pm 1.36 \mathrm{~mm}$ with LBD of $14.0 \pm 5.55 \mathrm{~mm}$, preoperatively. Patients with metastasis were treated with a marginal dose of $20.0 \pm 2.34$ Gy at the $50 \%$ isodose line with a median maximum dose of $44.0 \pm 5.52 \mathrm{~Gy}$. The median CTV was $1770 \pm 2791 \mathrm{~mm}^{3}$ (Table 2). Patients with uveal metastases had significantly decreased tumor thickness postoperatively $(\mathrm{p}=0.01)$. They did not have significant changes in VA, IOP, or LBD postoperatively (Table 3 ).

One out of seven patients (14.3\%) with uveal metastases was surviving at completion of the study. The final tumor thickness was $1.30 \pm 0.76 \mathrm{~mm}$ with an LBD of $13.50 \pm 9.62 \mathrm{~mm}$ (Table 1). One patient underwent enucleation for pain control. This patient presented with 10 out of 10 pain, presumed to be neuropathic in origin due to metastatic disease. The patient had macular degeneration in the eye not affected by metastasis with a VA of $20 / 50$, so GKR was attempted to spare the eye. Due to persistence of pain, the patient elected for enucleation. Of the six patients with uveal metastases who did not undergo enucleation, visual acuity increased by two or more lines in $14.3 \%(1 / 7)$, was stabilized in $28.6 \%(2 / 7)$, and decreased in $57.1 \%(4 / 7)$. Two of seven patients with choroidal metastases had recurrence at the same location as the previously treated lesions in the eye, but no extraocular progression was attributable to the eye. Of the two patients with recurrence, one had adenoid cystic carcinoma. The other had esophageal adenocarcinoma. It is possible that these tumors were less responsive to radiotherapy, required a higher dose, or were more malignant.

Dose to the margin, maximum dose of radiation, and CTV did not correlate with post-procedural VA, IOP, risk of enucleation, or death in patients with uveal metastases.

Of the patients with metastatic disease, 28.6\% (2/7) experienced local recurrence as defined by new choroidal 
lesions, and $14.3 \%(1 / 7)$ underwent enucleation for postprocedural neuropathic pain. Of note, this pain was present prior to GKR, but GKR was pursued instead of primary enucleation as the patient had macular degeneration and poor vision in the eye unaffected by the metastasis (Table 4).

\section{Discussion}

This clinical investigation of GKR for patients with choroidal metastasis and UM found a positive correlation existed for patients with uveal metastases between marginal dose and post-procedural intraocular pressure. Marginal dose, maximal dose, and CTV did not correlate with post-procedural VA, risk of enucleation, or death in patients with either UM or patients with uveal metastases. Though the marginal dose and the $50 \%$ isodose were determined and recorded, we did not have the dose to the lens or retina on these cases. This study provides new insights into outcomes of patients with UM and uveal metastases treated with GKR.

For treatment of UM, both GKR and proton beam radiotherapy have been shown to have similar outcomes as enucleation $[28,29]$. The COMS trial, which included more than 650 patients treated with plaque brachytherapy, found $88.7 \%$ of patients achieved local control with a recurrence rate of $10.3 \%$ and a survival rate of more than $80 \%$ at 5 years $[31,32]$.

Other studies on proton beam radiotherapy have demonstrated satisfactory outcomes. A prospective study by Gragoudas et al. reviewed 1922 consecutive patients treated with proton beam radiotherapy over $20+$ years with an average follow-up for patients was 5.2 years. Ninety-seven percent of patients achieved local tumor control with a recurrence rate of $4.9 \%$ ( 45 patients). Seventeen patients required enucleation due to suspected tumor progression [33, 34].

A study by Modorati et al. [1] of 78 patients with tumor thickness, ranging from 3.1 to $>10 \mathrm{~mm}$ over 12 years, treated with between 30 and 50 Gy (50\% isodose) with GKR, found a survival rate of $88.8 \%$ at 3 years and $81.9 \%$ at 5 years, which was independent of dose. After treatment, $91 \%$ of patients had local tumor control with median tumor thickness reduced by $1.9 \mathrm{~mm}$ from a median baseline of $6.1 \mathrm{~mm} ; 89.7 \%$ of patients avoided enucleation, although patients had significantly decreased vision after treatment (from 0.3 before treatment to an average VA of 0 ). Vision-compromising complications occurred such as exudative retinopathy (33.3\%), neovascular glaucoma (18.7\%), radiogenic retinopathy (13.5\%), and vitreous hemorrhages (10.4\%). Another study of single-fraction stereotactic radiosurgery of 23 patients applied 20-25 Gy (mean 21.7 Gy) and found $91 \%$ had local control. Three patients developed metastases in 121 months of follow-up, $61 \%$ of patients lost vision, $35 \%$ of patients maintained vision $>20 / 200$ [2]. The outcomes of our study are similar to these. Notably, our percent survival (63.6\%) is greater likely attributable to the shorter length of follow-up. Table 5 contains a review of other published studies on GKR for UM.

Evaluating outcomes of different treatment methods for ocular malignancies is key in determining the most efficacious treatments with the least amount of morbidity. Table 6 lists a summary of previous studies. In a study which included 36 patients with uveal metastases who underwent plaque treatment, 27 (75\%) received plaque brachytherapy as first-line treatment; 9 (25\%) patients received plaque treatment as secondary therapy after the tumor failed to respond to external beam radiotherapy, chemotherapy, or hormone treatment [35]. Patients were treated for an average time of $86 \mathrm{~h}$ with a mean dose of 68.80 Gy to the apex and 235.64 Gy to the base. Over 11 months, 34 patients (94\%) demonstrated regression. Five of six eyes receiving plaque brachytherapy as a second-line treatment were successfully salvaged. Three patients experienced radiation retinopathy, radiation papillopathy, or both (8\%) at a mean of 8 months after treatment. Fifty percent of patients survived to completion of the study [35]. Other studies have demonstrated acceptable results [36]. While these results are satisfactory, plaque radiotherapy was not an option for the patients in this study, given the size of patients' lesions. It is also true that GKR spared patients an additional procedure-plaque placement, required for plaque radiosurgery.

Proton beam therapy has also been demonstrated to have satisfactory results $[37,38]$. A retrospective study, which included 55 eyes of 49 patients who underwent two fractions of 14 cobalt gray equivalents, found that tumor regression occurred in $84 \%$ of patients and stability occurred in $14 \%$ of patients. Forty-seven percent of patients had vision that remained stable or improved. Post-proton therapy complications occurred in $29 \%$ of patients, including madarosis $(28 \%)$, lid burns (17\%), iris neovascularization and neovascular glaucoma (8\%), cataract $(11 \%)$, radiation maculopathy (19\%), and radiation papillopathy (22\%) [38]. During the dates of this study, proton therapy was not yet available at Mayo Clinic Rochester; therefore, patients ineligible for plaque therapy were treated with stereotactic radiosurgery.

A stereotactic radiosurgery study, which included ten patients with choroidal metastases, found that local tumor control was achieved in all eyes. Eight of ten patients had decreased tumor size. No significant side effects were noted in follow-up of 1-34 months [8]. While this study only included ten patients, it is notable that they did not experience significant side effects. 


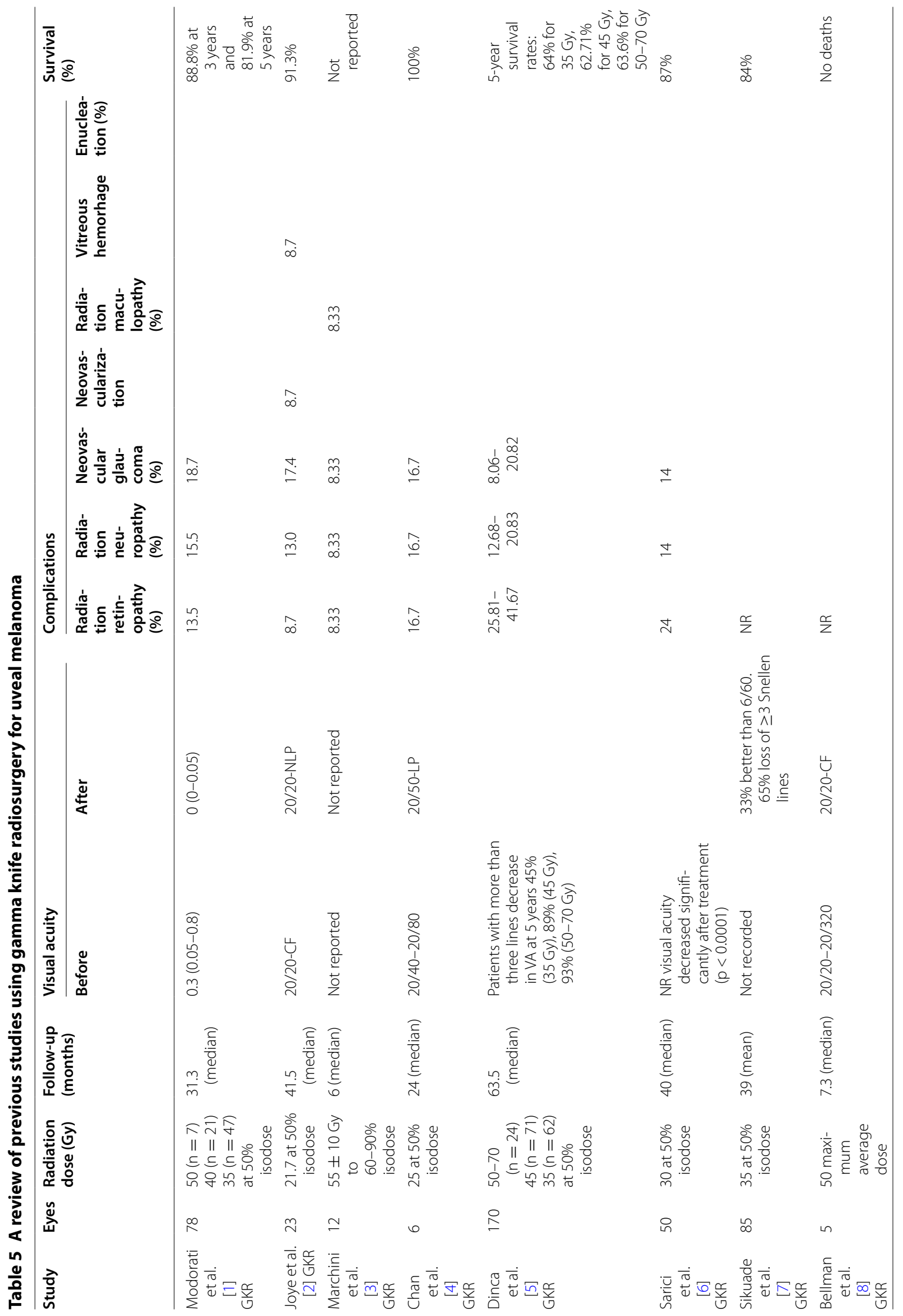




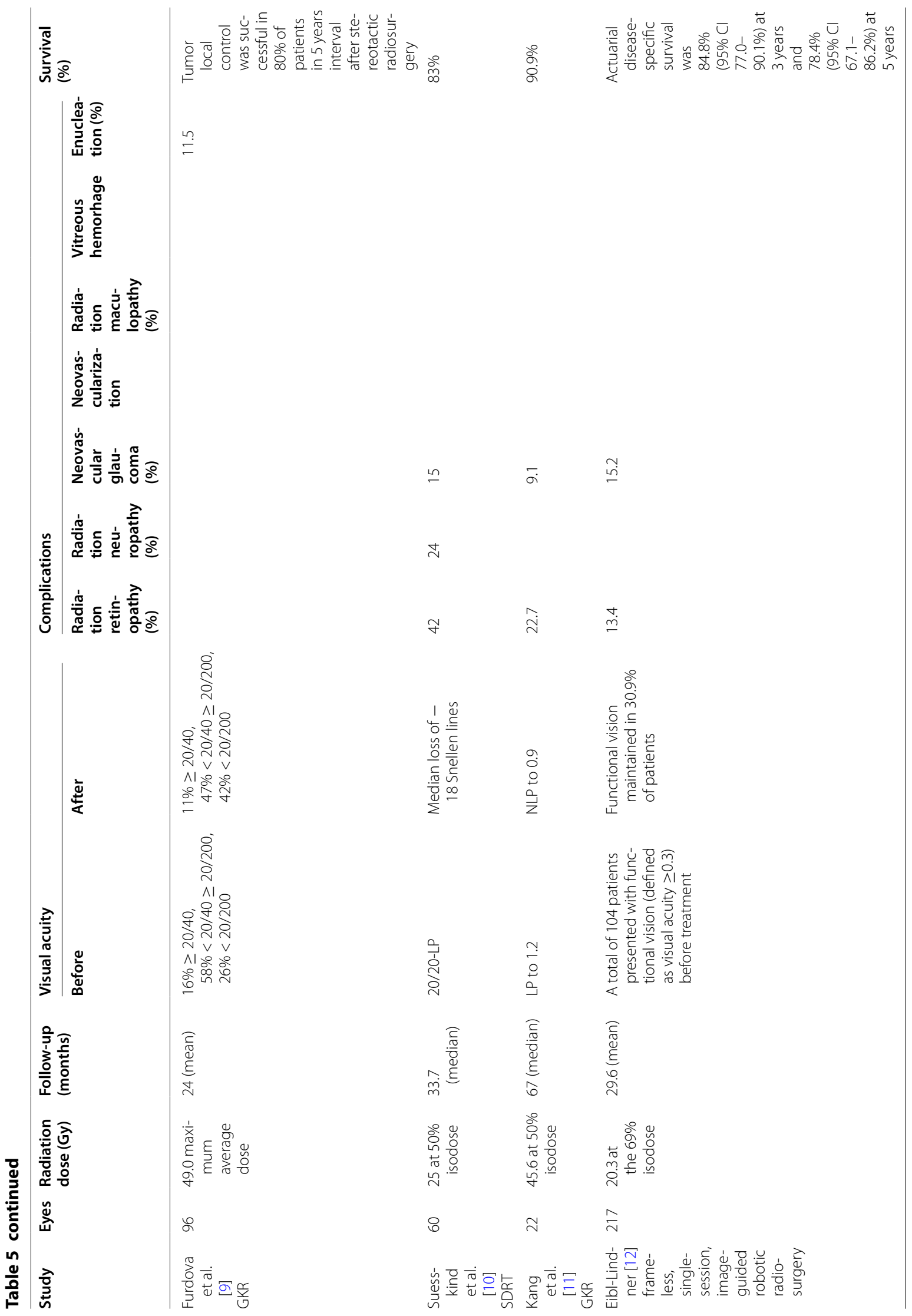




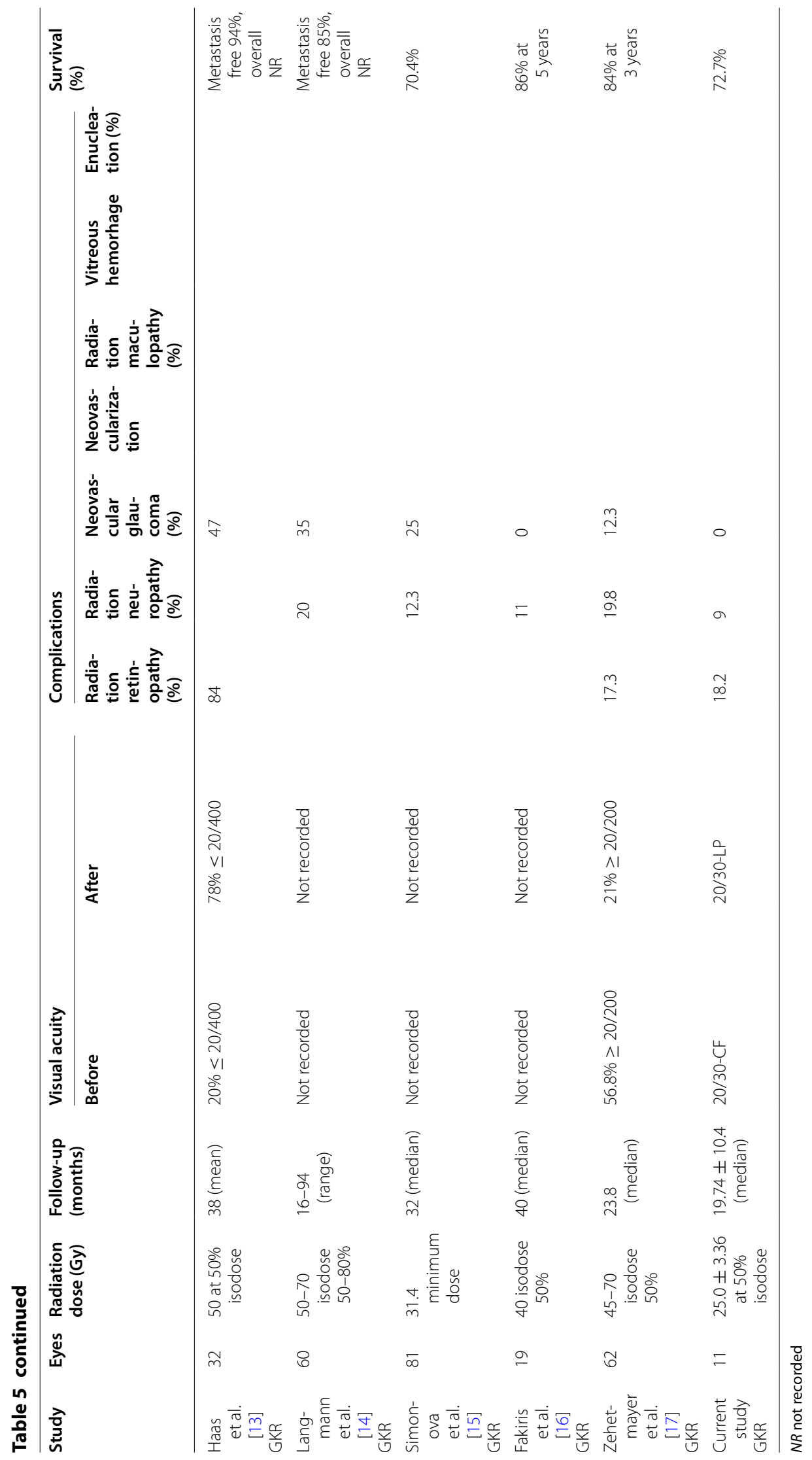




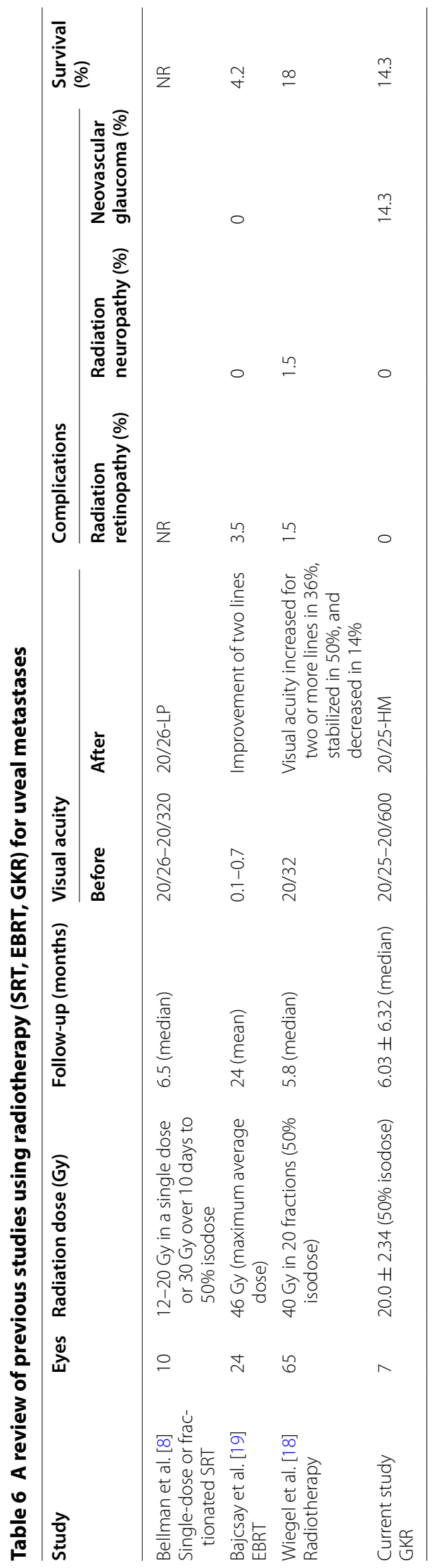


A review of other studies which looked at radiation and uveal metastases is reviewed in Table 5 .

Comparing the study published in this paper to those discussed, it had a higher rate of recurrence (28.6\%). Notably, patients included in this study had more rare metastatic cancers (as opposed to breast or lung cancer) and a lower survival rate (28.6\%). Weaknesses of this study included retrospective design, a small patient size, limited follow-up, and limited information regarding dose to the macula and optic nerve.

\section{Conclusions}

In summary, GKR is a useful alternative to plaque brachytherapy and proton beam therapy. It is particularly useful for patients who cannot or prefer not to undergo the procedures required for plaque brachytherapy or for whose tumor sizes disqualify them. It is also useful for patients who do not have access to proton beam therapy, which is geographically limited.

\begin{abstract}
Abbreviations
COMS: Collaborative Ocular Melanoma Treatment Study; CTV: clinical target volume; GKR: gamma knife radiosurgery; GTV: gross tumor volume; IOP: intraocular pressure; LBD: largest-base dimension; MRI: magnetic resonance imaging; UM: uveal melanoma; VA: visual acuity.
\end{abstract}

\section{Authors' contributions}

MMR: Made substantial contributions to conception, design, acquisition of data, as well as analysis and interpretation of data; involved in drafting the manuscript and revising it critically for important intellectual content. ALA: Made substantial contributions to conception, design, acquisition of data, as well as analysis and interpretation of data; involved in drafting the manuscript and revising it critically for important intellectual content. IFP: Made substantial contributions to conception, design, acquisition of data, as well as analysis and interpretation of data; involved in drafting the manuscript and revising it critically for important intellectual content. RK: Made substantial contributions to conception, design, acquisition of data, as well as analysis and interpretation of data; involved in drafting the manuscript and revising it critically for important intellectual content. NNL: Made substantial contributions to conception, design, acquisition of data; involved in drafting the manuscript and revising it critically for important intellectual content. PRM: Made substantial contributions to conception, design, acquisition of data, as well as analysis and interpretation of data; involved in drafting the manuscript and revising it critically for important intellectual content. TFK: Made substantial contributions to conception, design, acquisition of data, as well as analysis and interpretation of data; involved in drafting the manuscript and revising it critically for important intellectual content. YIG: Made substantial contributions to conception, design, acquisition of data; involved in drafting the manuscript and revising it critically for important intellectual content. RLF: Made substantial contributions to conception, design, acquisition of data; involved in drafting the manuscript and revising it critically for important intellectual content. JSP: Made substantial contributions to conception, design, acquisition of data, as well as analysis and interpretation of data; involved in drafting the manuscript and revising it critically for important intellectual content. All authors read and approved the final manuscript.

\section{Author details}

${ }^{1}$ Department of Ophthalmology, Mayo Clinic, 200 First Street, SW, Rochester, MN 55905, USA. ${ }^{2}$ Department of Radiation Oncology, Mayo Clinic, Rochester, MN, USA. ${ }^{3}$ Department of Neurosurgery, Mayo Clinic, Rochester, MN, USA. ${ }^{4}$ Department of Molecular Medicine, Mayo Clinic, 200 First Street, SW, Rochester, MN 55905, USA.
Acknowledgements

The authors Mrs. Denise Chase for her formatting help.

\section{Competing interests}

The authors declare that they have no competing interests.

\section{Availability of data and materials}

The datasets used and/or analyzed during the current study are available from the corresponding author on reasonable request.

\section{Ethics approval and consent to participate}

This study was approved by the IRB Committee of the Mayo Clinic following review of the Protocol 13-000260 institutional review of all radiosurgery cases for ocular lesions.

\section{Funding}

Supported, in part, by an unrestricted grant from Research to Prevent Blindness Inc., NY; VRS Foundation, Minneapolis, MN; the Paul Family; and the Deshong Fund.

Received: 18 January 2017 Accepted: 2 March 2017

Published online: 29 May 2017

\section{References}

1. Modorati G, Miserocchi E, Galli L, Picozzi P, Rama P. Gamma knife radiosurgery for uveal melanoma: 12 years of experience. Br J Ophthalmol. 2009;93:40-4. doi:10.1136/bjo.2008.142208.

2. Joye RP, Williams LB, Chan MD, Witkin AJ, Schirmer CM, Mignano JE, et al. Local control and results of Leksell gamma knife therapy for the treatment of uveal melanoma. Ophthalmic Surg Lasers Imaging Retina. 2014;45:125-31. doi:10.3928/23258160-20140306-05.

3. Marchini G, Babighian S, Tomazzoli L, Gerosa MA, Nicolato A, Bricolo A, et al. Stereotactic radiosurgery of uveal melanomas: preliminary results with gamma knife treatment. Stereotact Funct Neurosurg. 1995;64(Suppl. 1):72-9.

4. Chan MD, Melhus CS, Mignano JE, Do-Dai D, Duker JS, Yao KC. Analysis of visual toxicity after gamma knife radiosurgery for treatment of choroidal melanoma: identification of multiple targets and mechanisms of toxicity. Am J Clin Oncol. 2011;34:517-23.

5. Dinca EB, Yianni J, Rowe J, Radatz MW, Preotiuc-Pietro D, Rundle P, et al. Survival and complications following gamma knife radiosurgery or enucleation for ocular melanoma: a 20-year experience. Acta Neurochir. 2012;154:605-10. doi:10.1007/s00701-011-1252-6.

6. Sarici AM, Pazarli H. Gamma-knife-based stereotactic radiosurgery for medium- and large-sized posterior uveal melanoma. Graefes Arch Clin Exp Ophthalmol. 2013;251:285-94. doi:10.1007/s00417-012-2144-z.

7. Sikuade MJ, Salvi S, Rundle PA, Errington DG, Kacperek A, Rennie IG. Outcomes of treatment with stereotactic radiosurgery or proton beam therapy for choroidal melanoma. Eye. 2015;29:1194-8. doi:10.1038/ eye.2015.109.

8. Bellmann C, Fuss M, Holz FG, Debus J, Rohrschneider K, Volcker HE, et al. Stereotactic radiation therapy for malignant choroidal tumors: preliminary, short-term results. Ophthalmology. 2000;107:358-65.

9. Furdova A, Sramka M, Chorvath M, Kralik G, Krasnik V, Krcova I, et al. Stereotactic radiosurgery in intraocular malignant melanoma-retrospective study. Neuro Endocrinol Lett. 2014;35:28-36.

10. Suesskind D, Scheiderbauer J, Buchgeister M, Partsch M, Budach W, Bartz-Schmidt KU, et al. Retrospective evaluation of patients with uveal melanoma treated by stereotactic radiosurgery with and without tumor resection. JAMA Ophthalmol. 2013;131:630-7. doi:10.1001/ jamaophthalmol.2013.697.

11. Kang DW, Lee SC, Park YG, Chang JH. Long-term results of gamma knife surgery for uveal melanomas. J Neurosurg. 2012;117(Suppl):108-14. doi:1 0.3171/2012.8.GKS121002.

12. Eibl-Lindner K, Furweger C, Nentwich M, Foerster P, Wowra B, Schaller $U$, et al. Robotic radiosurgery for the treatment of medium and large uveal melanoma. Melanoma Res. 2016;26:51-7. doi:10.1097/ CMR.0000000000000199. 
13. Haas A, Pinter O, Papaefthymiou G, Weger M, Berghold A, Schrottner O, et al. Incidence of radiation retinopathy after high-dosage single-fraction gamma knife radiosurgery for choroidal melanoma. Ophthalmology. 2002;109:909-13.

14. Langmann G, Pendl G, Klaus M, Papaefthymiou G, Guss H. Gamma knife radiosurgery for uveal melanomas: an 8-year experience. J Neurosurg. 2000;93(Suppl. 3):184-8. doi:10.3171/jns.2000.93.supplement.

15. Simonova G, Novotny J Jr, Liscak R, Pilbauer J. Leksell gamma knife treatment of uveal melanoma. J Neurosurg. 2002;97:635-9. doi:10.3171/ jns.2002.97.supplement.

16. Fakiris AJ, Lo SS, Henderson MA, Witt TC, Worth RM, Danis RP, et al. Gamma-knife-based stereotactic radiosurgery for uveal melanoma. Stereotact Funct Neurosurg. 2007;85:106-12. doi:10.1159/000098525.

17. Zehetmayer M. Stereotactic photon beam irradiation of uveal melanoma. Dev Ophthalmol. 2012;49:58-65. doi:10.1159/000328259.

18. Wiegel T, Bottke D, Kreusel KM, Schmidt S, Bornfeld N, Foerster MH, et al. External beam radiotherapy of choroidal metastases - final results of a prospective study of the German Cancer Society (ARO 95-08). Radiother Oncol. 2002;64:13-8.

19. Bajcsay A, Kontra G, Recsan Z, Toth J, Fodor J. Lens-sparing external beam radiotherapy of intraocular metastases: our experiences with twenty four eyes. Neoplasma. 2003;50:459-64.

20. Chen CJ, McCoy AN, Brahmer J, Handa JT. Emerging treatments for choroidal metastases. Surv Ophthalmol. 2011;56:511-21. doi:10.1016/j. survophthal.2011.05.001.

21. Albert DM, Rubenstein RA, Scheie HG. Tumor metastasis to the eye. I. Incidence in 213 adult patients with generalized malignancy. Am J Ophthalmol. 1967;63:723-6.

22. Bloch RS, Gartner S. The incidence of ocular metastatic carcinoma. Arch Ophthalmol. 1971;85:673-5.

23. Nelson CC, Hertzberg BS, Klintworth GK. A histopathologic study of 716 unselected eyes in patients with cancer at the time of death. Am J Ophthalmol. 1983;95:788-93.

24. Wiegel T, Kreusel KM, Bornfeld N, Bottke D, Stange M, Foerster MH, et al. Frequency of asymptomatic choroidal metastasis in patients with disseminated breast cancer: results of a prospective screening programme. Br J Ophthalmol. 1998;82:1159-61.

25. Shields CL, Shields JA, Gross NE, Schwartz GP, Lally SE. Survey of 520 eyes with uveal metastases. Ophthalmology. 1997;104:1265-76.

26. Weiss L. Analysis of the incidence of intraocular metastasis. Br J Ophthalmol. 1993;77:149-51.
27. Singh AD, Turell ME, Topham AK. Uveal melanoma: trends in incidence, treatment, and survival. Ophthalmology. 2011;118:1881-5. doi:10.1016/j. ophtha.2011.01.040.

28. Lund RW. The Collaborative Ocular Melanoma Study, mortality by therapeutic approach, age and tumor size. J Insur Med. 2013;43:221-6.

29. Koutsandrea C, Moschos MM, Dimissianos M, Georgopoulos G, Ladas I. Apostolopoulos M. Metastasis rates and sites after treatment for choroidal melanoma by proton beam irradiation or by enucleation. Clin Ophthalmol. 2008;2:989-95.

30. Safaee M, Burke J, McDermott MW. Techniques for the application of stereotactic head frames based on a 25-year experience. Cureus. 2016;8:e543. doi:10.7759/cureus.543.

31. Diener-West M, Earle JD, Fine SL, Hawkins BS, Moy CS, Reynolds SM, et al. The COMS randomized trial of iodine 125 brachytherapy for choroidal melanoma, III: initial mortality findings. COMS Report No. 18. Arch Ophthalmol. 2001;119:969-82.

32. Jampol LM, Moy CS, Murray TG, Reynolds SM, Albert DM, Schachat AP, et al. The COMS randomized trial of iodine 125 brachytherapy for choroidal melanoma: IV. Local treatment failure and enucleation in the first 5 years after brachytherapy. COMS Report No. 19. Ophthalmology. 2002;109:2197-206.

33. Gragoudas ES, Lane AM, Munzenrider J, Egan KM, Li W. Long-term risk of local failure after proton therapy for choroidal/ciliary body melanoma. Trans Am Ophthalmol Soc. 2002;100:43-8 (Discussion 8-9)

34. Li W, Gragoudas ES, Egan KM. Metastatic melanoma death rates by anatomic site after proton beam irradiation for uveal melanoma. Arch Ophthalmol. 2000;118:1066-70.

35. Shields CL, Shields JA, De Potter P, Quaranta M, Freire J, Brady LW, et al. Plaque radiotherapy for the management of uveal metastasis. Arch Ophthalmol. 1997;115:203-9.

36. Demirci H, Shields CL, Chao AN, Shields JA. Uveal metastasis from breast cancer in 264 patients. Am J Ophthalmol. 2003;136:264-71.

37. Kamran SC, Collier JM, Lane AM, Kim I, Niemierko A, Chen YL, et al. Outcomes of proton therapy for the treatment of uveal metastases. Int J Radiat Oncol Biol Phys. 2014;90:1044-50. doi:10.1016/j.jirobp.2014.08.003.

38. Tsina EK, Lane AM, Zacks DN, Munzenrider JE, Collier JM, Gragoudas ES. Treatment of metastatic tumors of the choroid with proton beam irradiation. Ophthalmology. 2005;112:337-43. doi:10.1016/j. ophtha.2004.09.013.

\section{Submit your next manuscript to BioMed Central and we will help you at every step:}

- We accept pre-submission inquiries

- Our selector tool helps you to find the most relevant journal

- We provide round the clock customer support

- Convenient online submission

- Thorough peer review

- Inclusion in PubMed and all major indexing services

- Maximum visibility for your research

Submit your manuscript at www.biomedcentral.com/submit 